\title{
A Bayesian Geo-Additive Modeling of Childhood Anemia in India
}

\section{Holendro Singh Chungkham}

Indian Statistical Institute North-East Centre at Tezpur

STRONG P MARBANIANG ( $\nabla$ marbaniangstrong@gmail.com )

International Institute for Population Sciences https://orcid.org/0000-0001-5347-1867

\section{Pralip Kumar Narzary}

Bodoland University

\section{Research article}

Keywords: Spatial effects, Geo-additive logistic regression, P-splines, Childhood anaemia

Posted Date: May 26th, 2021

DOl: https://doi.org/10.21203/rs.3.rs-551263/v1

License: (c) (i) This work is licensed under a Creative Commons Attribution 4.0 International License. Read Full License 
Title: "A Bayesian Geo-Additive Modeling of Childhood Anemia in India"

Holendro Singh Chungkham ${ }^{1}$, Strong P Marbaniang ${ }^{2 *}$, Pralip Kumar Narzary ${ }^{3}$

${ }^{1}$ Indian Statistical Institute, North-East Centre, Tezpur, Assam, India

${ }^{2}$ Department of Public Health \& Mortality studies, International Institute for Population Sciences, Mumbai, Maharashtra, India

${ }^{3}$ Department of Geography, Bodoland University, Kokrajhar, Assam, India

*Corresponding author name and email address: Strong P Marbaniang- marbaniangstrong@gmail.com 


\section{Abstract}

2 Background: The geographical differences that caused anaemia can be partially explained

3 by the variability in environmental factors, particularly nutrition and infections. The studies

4 failed to explain the non-linear effect of the continuous covariates on childhood anaemia. The

5 present paper aimed to investigate the risk factors of childhood anaemia in India with focus

6 on geographical spatial effect.

7

8 Methods: Geo-additive logistic regression models were fitted to the data to understand fixed 9 as well as spatial effects of childhood anaemia. Logistic regression was fitted for the categorical variable with outcomes (anaemia $(\mathrm{Hb}<11)$ and no anaemia $(\mathrm{Hb} \geq 11))$. Continuous covariates were modelled by the penalized spline and spatial effects were smoothed by the two-dimensional spline.

Results: At 95\% posterior credible interval, the influence of unobserved factors on childhood anaemia is very strong in the Northern and Central part of India. However, most of the states in North Eastern part of India showed negative spatial effects. A U-shape non-linear relationship was observed between childhood anaemia and mother's age. This indicates that mothers of young and old ages are more likely to have children who are anaemic; in particular mothers aged 15 years to about 25 years. Then the risk of childhood anaemia starts declining after the age of 25 years and it continues till the age of around 37 years, thereafter again starts increasing. Further, the non-linear effects of duration of breastfeeding on childhood anaemia show that the risk of childhood anaemia decreases till 29 months thereafter increases. 
1 Conclusion: Strong evidence of residual spatial effect to childhood anaemia in India.

2 Government child health programme should gear up in treating childhood anaemia by

3 focusing on known measurable factors such as mother's education, mother's anaemia status,

4 family wealth status, child fever, stunting, underweight, and wasting which have been found

5 to be significant in this study, attention should also be given to effects of unknown or

6 unmeasured factors to childhood anaemia at the community level. Special attention to these

7 unmeasurable factors should be focused in the states of central and northern India which have

8 shown significant positive spatial effects.

9 Keywords: Spatial effects, Geo-additive logistic regression, P-splines, Childhood anaemia.

\section{Background}

Anemia among children is still a major public health concern in both developed and developing countries. Anemia is a condition in which the number and size of red blood cells or haemoglobin concentration is lower than the established cut-off value (1). Haemoglobin is essential to carry oxygen and if the body has abnormal or low red blood cells or not enough haemoglobin level, there will be a reduced capacity of the blood to carry oxygen to the body tissues. Globally, anemia affects 1.6 billion people, of which $47.4 \%$ were preschool-age children (2). According to the World Health Organization (WHO), anemia is considered a severe public health problem if the prevalence is 40 percent or more (2). In India, 58.5\% percent of children between the age of 6 months to 5 years were anemic during 2015-2016 (3). Moreover, studies have acknowledged the high prevalence of anaemia in low and middle-income countries (4), with $67.6 \%$ and $65.6 \%$ preschool-age children in Africa and South-East Asia suffered from anaemia (2). 
1 Iron is an essential element of haemoglobin, and iron deficiency is the most common cause of

2 anaemia. However, deficiency in micronutrient-rich diet, Vitamin A, and Vitamin B12 could

3 be the reason for iron deficiency (5). Also, disease like diarrhea (6), malaria (7), helminth

4 infection, and hookworms (5) increased the risk of anemia. In India, due to various socio-

5 economic, cultural, and religious beliefs, dietary food habits also vary amongst the

6 population. Dietary pattern is an essential factor associated with iron intake and absorption.

7 For example, a vegetarian diet may increase the risk of anemia due to the lack of iron

8 fortification (8). Existing literature have also shown that socio-economic factors such as

9 lower maternal education, low economic status (9), and demographic factors such as age and

10 sex of a child (10) affect anaemia. Maternal health status during pregnancy had a significant impact on the health and nutritional status of the child. Evidence from previous studies reported that maternal anaemia, and child nutritional statuses such as wasting, stunting and underweight increased the risk of anaemia $(11,12)$. During the first 5 years of life, children are most vulnerable to iron-deficiency anaemia because of the increased iron requirements due to their rapid growth (13). Iron deficiency anaemia in children is a serious concern because it may increase childhood morbidity, impaired growth development, and have long term effects on cognitive development and school performance (13).

Accounting for geographical heterogeneity of anaemia and the possible cause of heterogeneity is vital for the allocation of health resources to prevent and control anaemia. According to Koissi \& Högnäs, (2013) ignorance of geographical heterogeneity due to unobserved characteristics could lead to biased estimation of the parameters (14). Geographical heterogeneity could be the effect of the unmeasured factors, which means that the geographical differences of factors that caused anaemia can be partially explained by the variability in environmental (15). Malaria which caused anaemia are known to be associated with altitude and weather conditions such as temperature and rainfall (16). Similarly, soil- 
1 transmitted helminth infection, which caused anaemia is influence by the distance to water

2 bodies, surface temperature, index of vegetation and rainfall (17). There are a number of

3 studies using different statistical models such as multilevel and spatial mixed model to

4 determine the effect of geographical heterogeneity on childhood anaemia in India $(9,10)$;

5 however, all these studies have overlooked the advantage of using the bivariate spline in

6 modelling geographical heterogeneity. Specifically, the above model failed to explain the

7 non-linear effect of the continuous covariates on childhood anaemia.

8 Thus, the pioneering contribution of this study would be to explore the spatial variation of 9 anaemia among children aged 6 to 59 months using the spatial mixed model by assuming the 10 flexible approach of bivariate splines. More, specifically we want to explore the spatial 11 effects on childhood anaemia which arise due to the unmeasured factors. Identifying the 12 spatial clustering of anaemia and its associated risk factors may help improving the allocation 13 of health resources.

\section{Methods}

Study area and data

The study used the fourth round of the Indian National Family and Health Survey (20152016) which adopted a multi-stage stratified cluster sampling design (18). A total of 699686 eligible women between 15-49 years of age completed the interview. The whole data for the present study use child as the unit of analysis, rather than the mother itself. Information was available on 259627 children born in the last five years preceding the survey. The present study excluded the two union territories, Andaman \& Nicobar and Lakswdeep as their borders are not connected to the map of India as this will create problem in the estimation of 
1 spatial effects. Children with missing haemoglobin level were dropped from the analysis.

2 With this criterion the final analytical sample size of children was 208707.

3 The covariates in the present study were selected based on previous study (15). The outcome

4 variable used in the analysis was based on the categorization of haemoglobin level of children

5 adjusted for altitude giving a binary variable where children whose haemoglobin level was

6 less than $11 \mathrm{Hb}$ was categorised as being anaemic otherwise not anaemic. Mother educational

7 level, household wealth index, child cough, child fever, received vitamin A, mother anaemia

8 status, child stunting, wasting, underweight, child birth weight, child birth order, family size,

9 child age, mother age. Duration of breast feeding, child age, and mother age were treated as

10 continuous variables. However, the standard -2SD cut off values of z-scores categorization of

11 height for age, weight for height, and weight for age were used to characterize stunting,

12 wasting and underweight respectively.

\section{Statistical analysis}

Multiple logistic regression model was employed to select potential covariates for childhood anaemia prior to spatial analysis. A significance level of $20 \%$ was set for the selection of potential covariates to allow for selection of more variables to be used in the further analysis of spatial modelling.

Geo-additive logistic regression models were fitted to the data to understand fixed as well as spatial effects of childhood anaemia. If $p_{i j}$ is the probability that child $j$ from location $i$ being anaemic, then child anaemic status which is binary is distributed as Bernoulli $\left(p_{i j}\right)$. The following models were fitted to estimate fixed and spatial effects. 
$M 1: \operatorname{logit}\left(p_{i j}\right)=z_{i}^{s} \beta+f_{1}\left(u_{i 1}\right)+f_{1}\left(u_{i 2}\right)+\cdots+f_{1}\left(u_{i p}\right)$

$M 2: \operatorname{logit}\left(p_{i j}\right)=z_{i}^{\prime} \beta+f_{\text {spatial }}\left(S_{i}\right)$

M3: logit $\left(p_{i j}\right)=z_{i}^{g} \beta+f_{1}\left(u_{i 1}\right)+f_{1}\left(u_{i 2}\right)+\cdots+f_{1}\left(u_{i p}\right)+f_{\text {spatial }}\left(S_{i}\right)$

All categorical and continuous variables were treated as fixed effects in $M 0$. In case of $M 1$, categorical variables were employed as fixed effects and continuous variables were modelled by non-parametric smooth functions $f_{j} s$. Model $M 2$ included a spatial effect of the state where a child belongs in addition to the fixed effects of categorical variables. Finally, $M 3$ was a combination of $M 1$ and $M 2$. The smooth functions $f_{j} s$ were assigned with P-spline priors and the spatial component $f_{\text {spatial }}\left(S_{i}\right)$ with Markov random field prior $(19,20)$. A fully integrated Bayesian approach was adopted to estimate the parameters and the estimated posterior odds ratio $(\mathrm{OR})$ can be interpreted as the odds ratio from the logistic regression models. The models were fitted using the freely available package bamlss (21) in $R$ ( $R$ Core Team, 2020). A total of 40,000 MCMC iterations and 10,000 number of burn in samples were used in the analysis. Convergence of models were checked through autocorrelations and sampling paths. Finally, models were compared by Deviance Information Criterion (DIC) values (22), where the model with the smallest value is the preferred one. The DIC is calculated as $D I C=\bar{D}+p_{D}$, where $\bar{D}$ is the posterior mean of the model deviance, which gives a measure of goodness of fit, and $p_{D}$ is the effective number of parameters describing the complexity of the model and controls for penalty for model over fitting.

\section{Results}

\section{Descriptive results}


1 Table 1 provides prevalence of childhood anaemia according to region and states in India.

2 Northern, central and, eastern regions show high prevalence of anaemia compared to other

3 regions. The prevalence is above $60 \%$ in these three regions. The states of Chandigarh and

4 Haryana show relatively high prevalence of anaemia of about $73 \%$ and $72 \%$ in northern

5 region. In the central region, Madhya Pradesh and Uttar Pradesh show relatively high

6 prevalence of anaemia. Jharkhand and Bihar are the states in eastern region having relatively

7 high prevalence of anaemia of about $70 \%$ and $64 \%$ respectively. Most of the states in the

8 north-eastern region show comparatively low prevalence of anaemia ranging from $24 \%$ to

$957 \%$. The states of Karnataka and Telangana show relatively high prevalence of anaemia

10 above $60 \%$. The overall prevalence of anaemia in India is about $58 \%$.

11 Table 1: State variation of childhood anaemia

\begin{tabular}{lcc}
\hline Region/State & $\begin{array}{c}\text { Percentage of children } \\
\text { (Anaemic) }\end{array}$ & $\begin{array}{c}\text { Number of cases with } \\
\text { anaemic children }\end{array}$ \\
\hline Northern & 62.2 & 21,765 \\
Chandigarh & 72.7 & 112 \\
Haryana & 72.3 & 4,725 \\
Himachal Pradesh & 58.1 & 1,324 \\
Jammu and Kashmir & 59.6 & 3,986 \\
Delhi & 61.3 & 627 \\
Punjab & 57.3 & 2,544 \\
Rajasthan & 60.9 & 8,447 \\
Central & 63.0 & 41,351 \\
Chhattisgarh & 42.9 & 3,060 \\
Madhya Pradesh & 69.7 & 14,015 \\
Uttar Pradesh & 63.8 & 21,468 \\
Uttarakhand & 59.1 & 2,808 \\
Eastern & 61.2 & 27,158 \\
Bihar & 63.6 & 13,332 \\
Jharkhand & 70.1 & 7,002 \\
Odisha & 48.6 & 4,393 \\
West Bengal & 55.6 & 2,431 \\
North-Eastern & 35.8 & 10,504 \\
Arunachal Pradesh & 53.3 & 1,956 \\
Assam & 35.7 & 2,838 \\
Manipur & 24.2 & 1,153 \\
Meghalaya & 48.7 & 1,706 \\
Mizoram & 23.9 & 975 \\
Nagaland & 26.2 & 908 \\
Sikkim & 56.6 & 457
\end{tabular}


Tripura

Southern

Andhra Pradesh

Karnataka

Kerala

Puducherry

Tamil Nadu

Telangana

Western

Dadra \& Nagar Haveli

Daman \& Diu

Goa

Gujarat

Maharashtra

India
48.1

54.7

58.2

62.1

36.0

43.8

51.5

64.3

58.2

83.9

72.4

48.3

63.7

52.9

57.6
511

10,806

1,246

3,818

742

408

3,461

1,131

8,524

220

205

174

3,839

4,086

120,108

1

2 Table 2 provides a comparison of childhood anaemia across categorical covariates and a test of significance difference between categories of each covariate by chi-square test. It is

4 evident that children from rural, mother with low education, household of poor economic

5 condition show higher prevalence of anaemia than respective counterparts. There is a clear

6 significant difference in childhood anaemia between levels of place of residence, mother's

7 education and household wealth. But the sex of child does not show any significance

8 difference in childhood anaemia. Children with fever shows a tendency of higher prevalence

9 of anaemia. It can also be seen that consumption of vitamin A supplement during childhood

10 is helpful to reduce prevalence of anaemia. Under nutrition of children also shows an increase

11 in prevalence of anaemia. At 5\% level of significance the categorical variables, place of

12 residence, mother's education, household economic status, child fever, vitamin A, stunting, wasting, underweight and, mother's anaemic status are all associated with childhood anaemic without controlling for other covariates. The categorical variables child birth order, household size, child birth weight show a non-significant effect on childhood anaemia at $20 \%$ level of significance in the preliminary analysis. Therefore, only categorical variables listed in Table 2 are included in the spatial logistic regression model in Table 4. 

model

\begin{tabular}{|c|c|c|c|}
\hline Factor & $\mathrm{N}(\%)$ & $P^{*}$ & Effect coding \\
\hline Place of residence & & $<0.001$ & \\
\hline Urban & $27,338(55.2)$ & & 1 \\
\hline Rural & $92,770(58.3)$ & & $-1^{\mathrm{R}}$ \\
\hline Sex of the child & & 0.644 & \\
\hline Male & $62,486(57.5)$ & & 1 \\
\hline Female & $57,622(57.6)$ & & $-1^{\mathrm{R}}$ \\
\hline Mother's education & & $<0.001$ & \\
\hline Primary & $17,845(58.3)$ & & 1 \\
\hline Secondary & $50,460(54.1)$ & & 2 \\
\hline Higher & $9,467(50.1)$ & & 3 \\
\hline No education & $42,336(64.3)$ & & $-1^{R}$ \\
\hline Wealth index & & $<0.001$ & \\
\hline Poor & $28,395(57.6)$ & & 1 \\
\hline Middle & $23,422(56.2)$ & & 2 \\
\hline Rich & $18,677(53.9)$ & & 3 \\
\hline Richest & $14,804(52.9)$ & & 4 \\
\hline Poorest & $34,810(63.2)$ & & $-1^{\mathrm{R}}$ \\
\hline Fever & & $<0.001$ & \\
\hline Yes & $16,729(60.9)$ & & 1 \\
\hline No & $103,295(57.1)$ & & $-1^{\mathrm{R}}$ \\
\hline Missing & $84(52.8)$ & & \\
\hline Cough & & 0.220 & \\
\hline Yes & $13,887(57.1)$ & & 1 \\
\hline No & $106,159(57.6)$ & & $-1^{\mathrm{R}}$ \\
\hline Missing & $62(54.9)$ & & \\
\hline Child received vitamin & & $>0.001$ & \\
\hline A & & & \\
\hline Yes & $38,674(58.1)$ & & 1 \\
\hline No & $80,003(57.3)$ & & $-1^{R}$ \\
\hline Missing & $1,431(57.1)$ & & \\
\hline Stunting & & $<0.001$ & \\
\hline Yes & $50,438(62.7)$ & & 1 \\
\hline No & $64,015(53.6)$ & & $-1^{\mathrm{R}}$ \\
\hline Missing & $5,655(63.9)$ & & \\
\hline Underweight & & $<0.001$ & \\
\hline Yes & $45,252(63.7)$ & & 1 \\
\hline No & $69,201(53.7)$ & & $-1^{R}$ \\
\hline Missing & $5,655(63.9)$ & & \\
\hline Wasting & & $<0.001$ & \\
\hline Yes & $8,814(64.1)$ & & 1 \\
\hline No & $105,639(56.8)$ & & $-1^{R}$ \\
\hline Missing & 5,655 (63.9) & & \\
\hline Mother anaemic & & $<0.001$ & \\
\hline Yes & $48,928(67.8)$ & & 1 \\
\hline No & $70,787(52.1)$ & & $-1^{R}$ \\
\hline Missing & $393(58.1)$ & & \\
\hline
\end{tabular}


The selection of the most preferred model is based on the deviance information criterion

4 (DIC) and deviance values. Model with the smallest values of DIC and deviance is the

5 preferred model. With this criteria, model $M 3$ is the preferred model (Table 3). Therefore,

6 interpretations of results (Table 4) and discussions are based on model M3.

$7 \quad$ Table 3: Model comparison by deviance information criterion (DIC)

\begin{tabular}{cccc}
\hline Model Fit & Deviance & $\mathrm{pD}$ & DIC \\
\hline M0 & 171173.90 & 19.79 & 171154.10 \\
M1 & 170885.30 & 37.71 & 170847.60 \\
M2 & 165233.90 & 51.77 & 165182.10 \\
M3 & 164909.50 & 69.92 & 164839.60 \\
\hline
\end{tabular}

8

9 Table 4 shows fixed effects to childhood anaemia. Place of residence, mother's education,

\subsection{Fixed effects}

poorest, rich, richest categories of household wealth, fever, cough, child under nutrition and mother's anaemic status are fixed effects variables which are significant to childhood anaemia. The fixed effects coefficient for fever is positive, which indicates that children with fever are likely to increase the risk of childhood anaemia. Children who take vitamin A supplement decrease the likelihood of becoming anaemic. Children from rich or richest quintile of household wealth also have lesser risk of childhood anaemia than those who belong to poorest quintile. Children who are malnourished increase the risk of childhood anaemia. Mother's anaemic status has a positive effect on childhood anaemia. This means that children whose mothers are anaemic have higher risk of being anaemic than those whose mothers are not anaemic.

20 Table 4: Fixed effects on children anaemia in India

\begin{tabular}{llllll}
\hline Variable & Mean & SD & $10 \%$ & Median & $90 \%$ \\
\hline Place of residence & & & & &
\end{tabular}




$$
\text { Rural }^{\mathrm{R}}
$$

Urban

Sex of child

Female $^{\mathrm{R}}$

Male

Mother's education

No education ${ }^{\mathrm{R}}$

Primary

Secondary

Higher

$0.0359 *$

0.008

0.0262

0.0355

0.0461

Wealth index

Poorest $^{\mathrm{R}}$

Poor

Middle

Rich

Richest

Child had fever

$\mathrm{No}^{\mathrm{R}}$

Yes

Child had cough

$\mathrm{No}^{\mathrm{R}}$

Yes

Child received vitamin

A

$$
\mathrm{No}^{\mathrm{R}}
$$

Yes

Child stunted

$\mathrm{No}^{\mathrm{R}}$

Yes

Child underweight

$\mathrm{No}^{\mathrm{R}}$

Yes

Child wasted

$$
\mathrm{No}^{\mathrm{R}}
$$

Yes

$0.0740^{*}$

0.0069

$-0.0904 *$

$-0.1332 *$

0.012

0.012

0.013

0.017

$-0.0003$

0.0075

0.0148

$0.0563 * \quad 0.014$

0.0386

0.0564

$-0.0361$

$-0.1844$

0.0740

$-0.0481$

$-0.2056$

$-0.0229$

$-0.1625$

$\begin{array}{ll}-0.0358 * & 0.010 \\ -0.1843 * & 0.016\end{array}$

0.0585

$-0.0079$

$-0.1072$

$-0.1548$

0.0736

0.0071

$-0.0904$

$-0.1330$

0.0893

0.0222

$-0.0736$

$-0.1125$

$\begin{array}{lll}0.0326 * & 0.010 & 0.0200\end{array}$

0.0327

0.0451

$-0.0594 *$

0.010

$-0.0723$

$-0.0596$

$-0.0466$

Mother anaemic $\mathrm{No}^{\mathrm{R}}$

1

Yes

${ }^{R}$ : Reference category. ${ }^{*}$ :Statistically significant at $5 \%$ alpha.

$2 \quad$ Non-linear effects

3 Another reason behind the geo-additive modelling is the ability to incorporate non-linear

4 effects of continuous variables. In the present study, we incorporated non-linear effects of age

5 of child, mother's age and, duration of breast feeding. 
1 Child age has non-linear effect to childhood anaemia (Fig 1). It is evident from Fig 1 that as

2 child age increases, its effect on child anaemia decreases, which indicates, older children are

3 less likely to have the risk of childhood anaemia. The risk of having anaemia is much higher

4 in younger children aged about 6 months to about 15 months and decreases thereafter.

5 Fig 1. Non linear effect of child age to childhood anaemia. Lower and Upper lines indicate $95 \%$ 6 confidence interval

7 Mother age also has a non-linear effect to childhood anaemia (Fig 2). The functional 8 relationship between childhood anaemia and mother age depicts almost a U shape. This

9 indicates that mothers of young and old ages are more likely to have children who are anaemic; in particular mothers aged15 years to about 25 years. Then the risk of childhood anaemia starts declining after the age of 25 years and it continuous till the age of around 37 years, thereafter again starts increasing.

Fig 2. Non linear effect of mother age to childhood anaemia. Lower and Upper lines indicate $95 \%$ confidence interval

Fig 3 shows the non-linear effects of duration of breast feeding on childhood anaemia. The risk of childhood anaemia decreases till 29 months, thereafter increases. This indicates improvement in childhood anaemia with increase in duration of breast feeding. The credible intervals are wider at extreme ages because of small cases of observations.

Fig 3. Non linear effect of duration of breast feeding to childhood anaemia. Lower and Upper lines indicate $95 \%$ confidence interval.

21 Spatial effects

Fig 4 displays the estimates of the spatial effects of childhood anaemia, with colour range goes from black to white representing low to high risk of childhood anaemia. Spatial effects represent unobserved influences, such as environmental and climatic factors, availability of good transport facility, and access to good services for child health. The figure clearly shows evidence of residual spatial effects of childhood anaemia in India with most of states show 
1 significant positive/negative effects with respect to the $95 \%$ posterior credible interval map

2 (Fig 5). With respect to $80 \%$ posterior credible interval more states show significant spatial

effects (Fig 6). Most of states in northern and central regions show significant positive spatial effects with respect to $95 \%$ credible interval. However, almost all states in north-eastern region of India show significant negative spatial effects with regard to the $80 \%$ credible interval (Fig 6).

Fig 4. Residual spatial effect to childhood anaemia. Colour ranges from black to white representing low to high risk of childhood anaemia.

Fig 5. The $95 \%$ credible intervals map for prevalence of anaemia. White: negative effect; light black: insignificant effect; black: positive effect.

Fig 6. The $80 \%$ credible intervals map for prevalence of anaemia. White: negative effect; light black: insignificant effect; black: positive effect.

\section{Discussion}

In India Childhood anaemia cuts across all the sections of society with varying intensity. Its prevalence as per the WHO classification is the indication that it is a severe public health problem for India. Except for Mizoram, Manipur, Nagaland, Assam, and Kerala for all the states and union territories (UTs,) anaemia is a matter of concern, whereas for states like Haryana, Jharkhand, and Madhya Pradesh it is of extremely serious concern. These three states need to revisit existing programs targeting to address the child health in general and anaemia in particular.

Anaemia has a close link with the food habit. Food habit is closely associated with culture and the nature. Geographical settings decide the nature of food supply and the micronutrients. Within the same geographical settings culture may encourage or discourage some group of population to consume or avoid certain nutritious food. For example tribal culture of northeast India approves consumption of varieties of insects, whereas for non-tribals 
1 consumption of such insects is considered as taboo. Probably because of this reason the tribal

2 dominated states like Mizoram, Manipur, and Nagaland have very low prevalence of anaemic

3 children. However, our finding contradicts other studies in India that children from lowest

4 socioeconomic strata have more likelihood of suffering from anaemia $(9,23)$ and Nepal (24).

5

6 The prevalence of anaemia among children in rural areas is comparatively higher than their

7 counter part in India. Rural mass in India might be less aware about the balanced diet which

8 has potentials to improve the hemoglobin count. Because as high as one third of rural

9 population in India are illiterate. Ignorance of food items relating to iron content food staff

10 may also add to the problem of anaemia in rural areas. This indicates that mass media

11 campaign to address anaemia should emphasize pictorial and or audio-visual means, rather than on the written leaflets. A distinct negative relationship between wealth quintile and child anaemia is quite evident. This is indicative of the fact that economically poorer households may not be able to afford to procure nutritious food. This calls for better public distribution system which provides subsidized food in India. The system need to keep an eye on regularity, quantity, quality, etc.

Uneducated mothers are less equipped with knowledge of hygiene and proper knowledge of child care. Unhealthy feeding habit can lead to various types of food related health problems. Feeding practice is closely associated with diahhroeal disease and studies exhibit that there is positive relationship between diahhroea and anemia. Unlike earlier studies $(8,10)$ no significant association is noted between sex of the child and prevalence of anaemia in the present study. Children who take vitamin A supplement decrease the likelihood of becoming anaemic. But earlier study (8) did not find significant statistical association between vitamin A intake and childhood anaemia. In India, poor and illiterate families leave their baby on the 
1 mud floor. The crawling baby in absence of any care taker may put to mouth anything it

2 comes to his hand. Such activities may lead to various infections, morbidities, that is why

3 younger children have more likelihood of suffering from anaemia. Other studies also indicate

4 that younger children have more chances of having anaemia $(15,24)$. Very young mothers

5 definitely are less educated and relatively old mothers might take child rearing for granted, as

6 they may already have older children. Other study also indicates U-shape relationship

7 between mother's age and the childhood anaemia (15) and others $(10,25)$ found children born

8 to young mothers are more likely to be anaemic.

10 In India usually the educated and rich women, due to various reasons, do not practice exclusive breast feeding. Exclusive breast feeding in India is usually practiced among the less educated and poor women, as a result a positive association between exclusive breast feeding and childhood anaemia is observed. However, this finding contradicts studies conducted elsewhere (26).

\section{Conclusions}

17 There is strong evidence of residual spatial effect to childhood anaemia in India. Government child health programme should gear up in treating childhood anaemia by focusing on known measurable factors such as mother's education, mother's anaemia status, family wealth status, child fever, stunting, underweight, and wasting which have been found to be significant in this study, attention should also be given to effects of unknown or unmeasured factors to childhood anaemia at the community level. Special attention to these unmeasurable factors should be focused in the states of central and northern India which have shown significant positive spatial effects. 
List of Abbreviation

DIC- Deviance Information Criterion

5 WHO- World Health Organisation

6 OR- Odds Ratio

7 UTs- Union Territories

8 HSC- Holendro Singh Chungkham

9 SPM- Strong P Marbaniang

PKN- Pralip Kumar Narzary

\section{Declarations}

Ethical approval and consent to participate: The 2015-16 Indian Demographic Health Survey data are available to the public by request from the DHS website https://dhsprogram.com/methodology/survey/survey-display-355.cfm. We submitted a request to the DHS by mentioning the objectives of this study and thereafter was granted the permission to download the dataset.

Consent for publication: Not applicable

Availability of data and materials: The datasets generated and/or analysed during the current study are available in the Website of Demographic Health Survey

21 https://dhsprogram.com/methodology/survey/survey-display-355.cfm

Competing interest: The authors declare that they have no competing interests

Funding: Not applicable

Author's contributions: HSC, SPM conceived the study, involved in the study design, data analysis, interpret the data, drafted the manuscript. PKN drafted the manuscript. All authors read and agreed on the submitted final manuscript.

Acknowledgement: Not applicable

Author's information:

HSC is an Associate Professor at the Indian Statistical Institute (ISI), North-East Centre, Tezpur, Assam, India. SPM is a Research Scholar in the Department of Public Health and Mortality Studies, International Institute for Population Sciences, Mumbai, Maharashtra, India. PKN is an Associate Professor in the Department of Geography, Bodoland University,

\section{References}


1 1. Kotwal A. Iron deficiency anaemia among children in South East Asia: Determinants, importance, prevention and control strategies. Curr Med Res Pract [Internet]. 2016 May;6(3):117-22. Available from: http://linkinghub.elsevier.com/retrieve/pii/S2352081716300654

2. Benoist B de, McLean E, Egli I, Cogswell M, editors. Worldwide prevalence of anaemia 1993-2005: WHO global database on anaemia [Internet]. World Health

3. International Institute for Population Sciences (IIPS) and ICF. National Family Health Organization; 2008 [cited 2020 Aug 10]. Available from: https://www.who.int/vmnis/anaemia/prevalence/en/ Survey (NFHS-4), 2015-16: India [Internet]. Mumbai:IIPS; 2017. Available from: http://rchiips.org/nfhs/NFHS-4Reports/India.pdf

4. McLean E, Cogswell M, Egli I, Wojdyla D, de Benoist B. Worldwide prevalence of anaemia, WHO Vitamin and Mineral Nutrition Information System, 1993-2005. Public Health Nutr [Internet]. 2009 Apr 23;12(04):444. Available from: http://www.journals.cambridge.org/abstract_S1368980008002401

5. Balarajan Y, Ramakrishnan U, Özaltin E, Shankar AH, Subramanian S. Anaemia in low-income and middle-income countries. Lancet [Internet]. 2011 Dec;378(9809):2123-35. Available from: https://linkinghub.elsevier.com/retrieve/pii/S0140673610623045

6. Howard CT, de Pee S, Sari M, Bloem MW, Semba RD. Association of diarrhea with anemia among children under age five living in rural areas of Indonesia. J Trop Pediatr [Internet]. 2007 Aug 1;53(4):238-44. Available from: https://academic.oup.com/tropej/article-lookup/doi/10.1093/tropej/fmm011

7. Calis JCJ, Phiri KS, Faragher EB, Brabin BJ, Bates I, Cuevas LE, et al. Severe Anemia in Malawian Children. N Engl J Med [Internet]. 2008 Feb 28;358(9):888-99. Available from: http://www.nejm.org/doi/abs/10.1056/NEJMoa072727

8. Ray R. Mother's autonomy and child anemia: A case study from India. Child Youth Serv Rev [Internet]. 2020 May;112(March):104537. Available from: https://doi.org/10.1016/j.childyouth.2019.104537

9. Sharma H, Singh SK, Srivastava S. Socio-economic inequality and spatial heterogeneity in anaemia among children in India: Evidence from NFHS-4 (2015-16). Clin Epidemiol Glob Heal [Internet]. 2020 Dec;8(4):1158-71. Available from: 
https://doi.org/10.1016/j.cegh.2020.04.009

10. Dutta M, Bhise M, Prashad L, Chaurasia H, Debnath P. Prevalence and risk factors of anemia among children 6-59 months in India: A multilevel analysis. Clin Epidemiol Glob Heal [Internet]. 2020 Sep;8(3):868-78. Available from: https://doi.org/10.1016/j.cegh.2020.02.015

11. Rahman MS, Mushfiquee M, Masud MS, Howlader T. Association between malnutrition and anemia in under-five children and women of reproductive age: Evidence from Bangladesh Demographic and Health Survey 2011. Adu-Afarwuah S, editor. PLoS One [Internet]. 2019 Jul 3;14(7):e0219170. Available from: https://dx.plos.org/10.1371/journal.pone.0219170

12. Engidaye G, Melku M, Yalew A, Getaneh Z, Asrie F, Enawgaw B. Under nutrition, maternal anemia and household food insecurity are risk factors of anemia among preschool aged children in Menz Gera Midir district, Eastern Amhara, Ethiopia: a community based cross-sectional study. BMC Public Health [Internet]. 2019 Dec 19;19(1):968. Available from: https://bmcpublichealth.biomedcentral.com/articles/10.1186/s12889-019-7293-0

13. WHO. Guideline: Intermittent iron supplementation in preschool and school-age children [Internet]. Geneva: World Health Organization, Geneva; 2011. Available from: https://www.who.int/nutrition/publications/micronutrients/guidelines/guideline_iron_s upplementation_children/en/

14. Koissi M-C, Högnäs G. Using WinBUGS to Study Family Frailty in Child Mortality, with an Application to Child Survival in Ivory Coast. African Popul Stud [Internet]. 2013 Nov 1;20(1):1-17. Available from: http://aps.journals.ac.za/pub/article/view/384

15. Ngwira A, Kazembe LN. Bayesian random effects modelling with application to childhood anaemia in Malawi. BMC Public Health [Internet]. 2015 Dec 19;15(1):161. Available from: http://bmcpublichealth.biomedcentral.com/articles/10.1186/s12889015-1494-y

16. Marbaniang SP, Ladusingh L. Meteorological Conditions and Malaria Cases-Study in the Context of Meghalaya. In: Issues on Health and Healthcare in India, India Studies in Business and Economics [Internet]. Singapore: Springer; 2018. p. 379-93. Available from: http://link.springer.com/10.1007/978-981-10-6104-2_21 
17. Soares Magalhães RJ, Salamat MS, Leonardo L, Gray DJ, Carabin H, Halton K, et al.

Mapping the Risk of Soil-Transmitted Helminthic Infections in the Philippines. Knopp S, editor. PLoS Negl Trop Dis [Internet]. 2015 Sep 14;9(9):e0003915. Available from: https://dx.plos.org/10.1371/journal.pntd.0003915

18. DHS. The DHS Program-India: Standard DHS, 2015-16 Dataset, [Internet]. Demographic Health Survey. 2017. Available from: https://dhsprogram.com/data/dataset/India_Standard-DHS_2015.cfm?flag=1

19. Fahrmeir L, Kneib T, Lang S. Penalized structured additive regression for space-time data: a Bayesian perspective. Stat Sin [Internet]. 2004;14:731-61. Available from: http://www3.stat.sinica.edu.tw/statistica/oldpdf/A14n36.pdf

20. Lang S, Brezger A. Bayesian P-Splines. J Comput Graph Stat [Internet]. 2004 Mar;13(1):183-212. Available from: http://www.tandfonline.com/doi/abs/10.1198/1061860043010

21. Umlauf N, Klein N, Zeileis A. BAMLSS: Bayesian Additive Models for Location, Scale, and Shape (and Beyond). J Comput Graph Stat [Internet]. 2018 Jul 3;27(3):61227. Available from: https://www.tandfonline.com/doi/full/10.1080/10618600.2017.1407325

22. Spiegelhalter DJ, Best NG, Carlin BP, van der Linde A. Bayesian measures of model complexity and fit. J R Stat Soc Ser B (Statistical Methodol [Internet]. 2002 Oct;64(4):583-639. Available from: http://doi.wiley.com/10.1111/1467-9868.00353

23. Goswmai S, Das KK. Socio-economic and demographic determinants of childhood anemia. J Pediatr (Rio J) [Internet]. 2015 Sep;91(5):471-7. Available from: http://dx.doi.org/10.1016/j.jped.2014.09.009

24. Khanal V, Karkee R, Adhikari M, Gavidia T. Moderate-to-severe anaemia among children aged 6-59 months in Nepal: An analysis from Nepal Demographic and Health Survey, 2011. Clin Epidemiol Glob Heal [Internet]. 2016 Jun;4(2):57-62. Available from: http://dx.doi.org/10.1016/j.cegh.2015.07.001

25. Onyeneho NG, Ozumba BC, Subramanian S V. Determinants of Childhood Anemia in India. Sci Rep [Internet]. 2019 Dec 12;9(1):16540. Available from: http://www.nature.com/articles/s41598-019-52793-3

26. Dalili H, Baghersalimi A, Dalili S, Pakdaman F, Hassanzadeh Rad A, Abbasi 
Kakroodi M, et al. Is there any relation between Duration of breastfeeding and anemia? Iran J Pediatr Hematol Oncol [Internet]. 2015;5(4):218-26. Available from: https://pubmed.ncbi.nlm.nih.gov/26985355/

4 
Figures

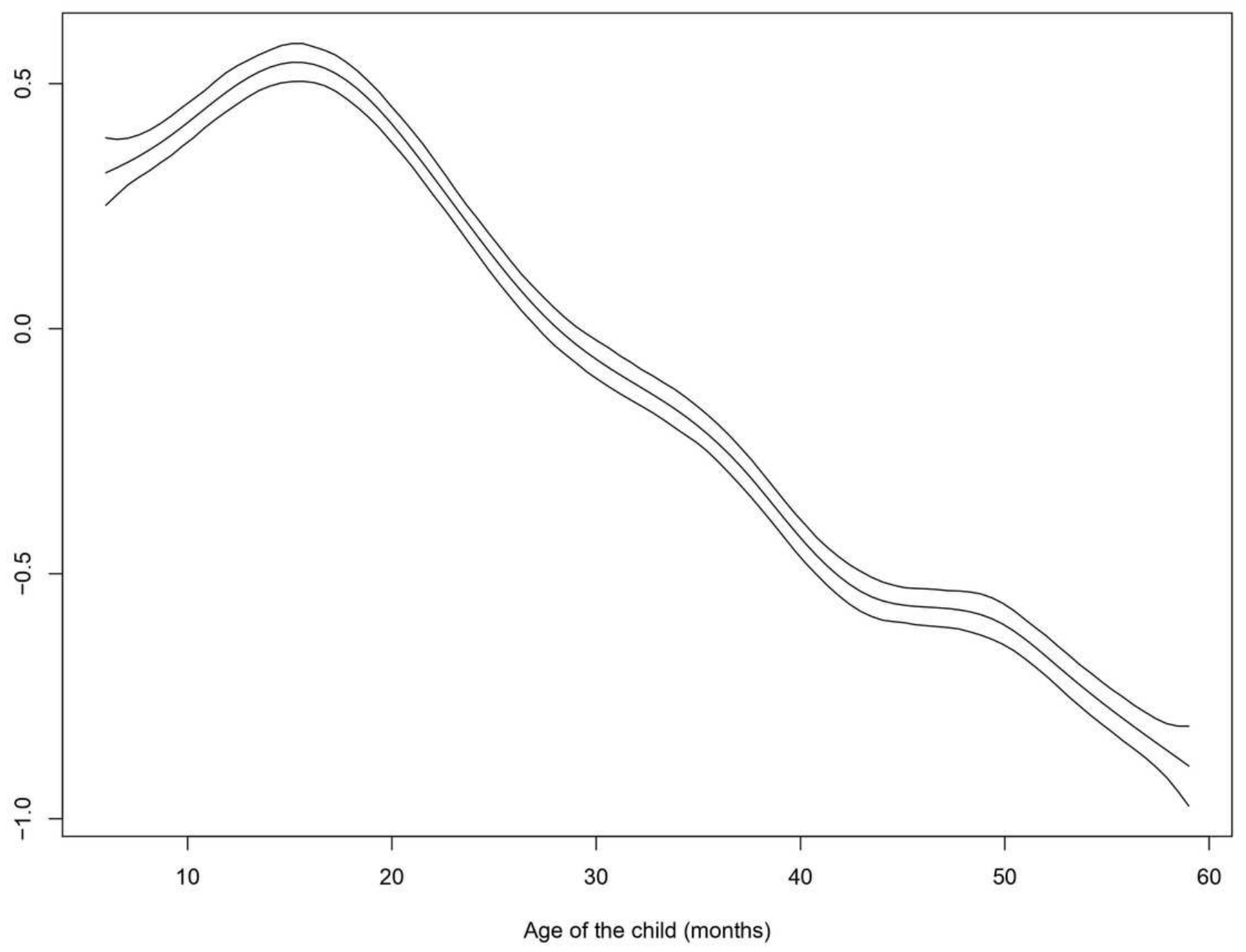

Figure 1

Non linear effect of child age to childhood anaemia. Lower and Upper lines indicate $95 \%$ confidence interval 


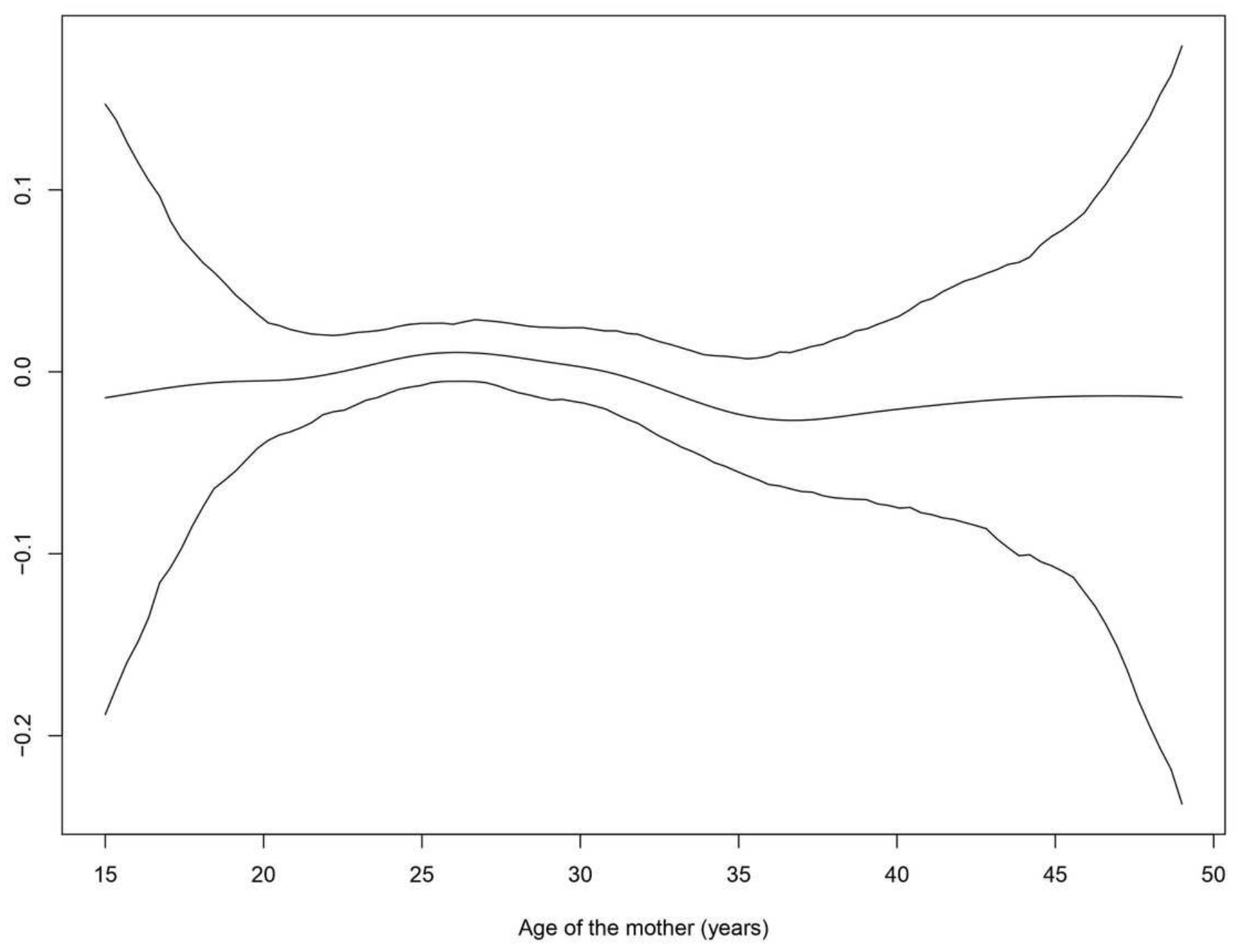

Figure 2

Non linear effect of mother age to childhood anaemia. Lower and Upper lines indicate $95 \%$ confidence interval 


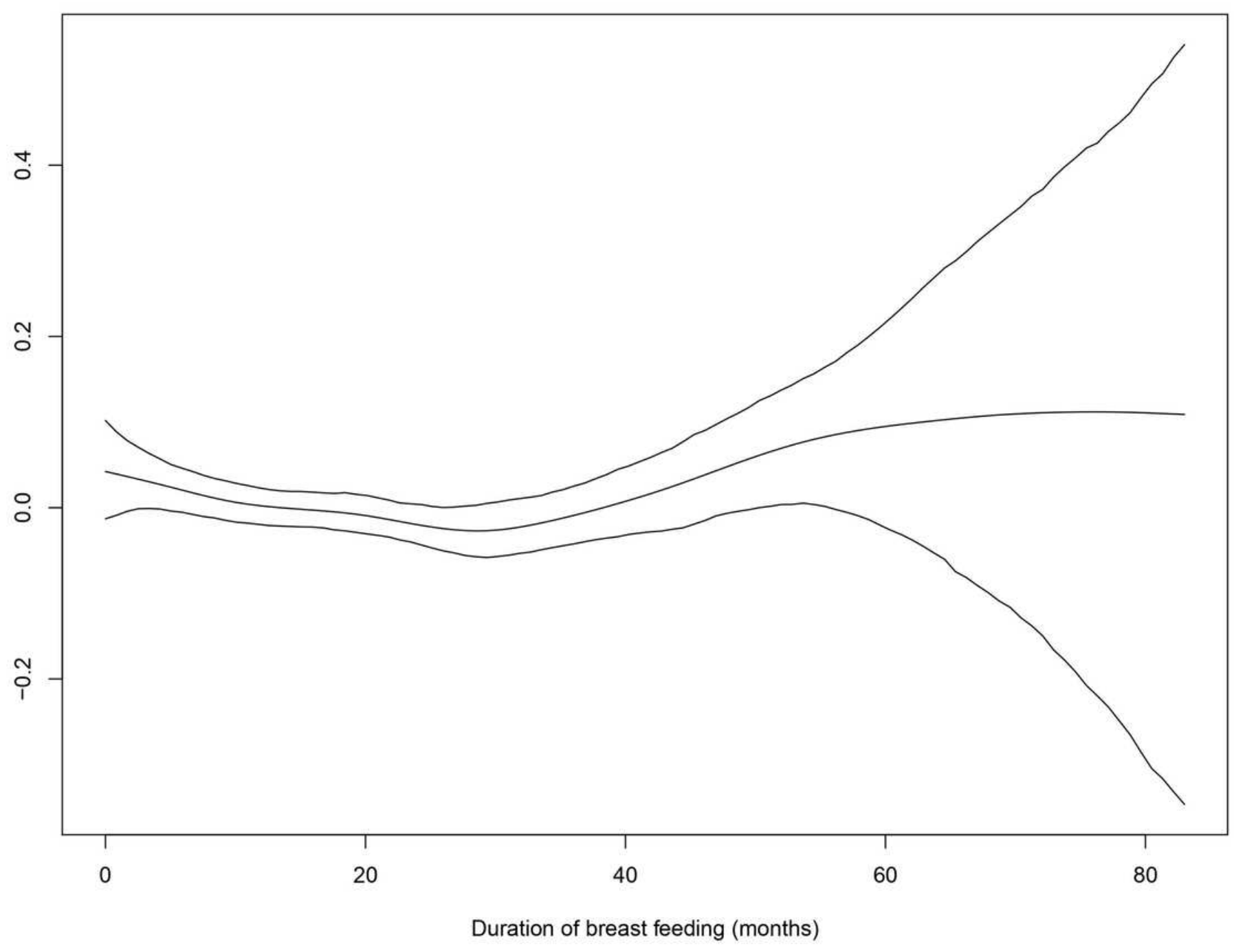

Figure 3

Non linear effect of duration of breast feeding to childhood anaemia. Lower and Upper lines indicate 95\% confidence interval. 


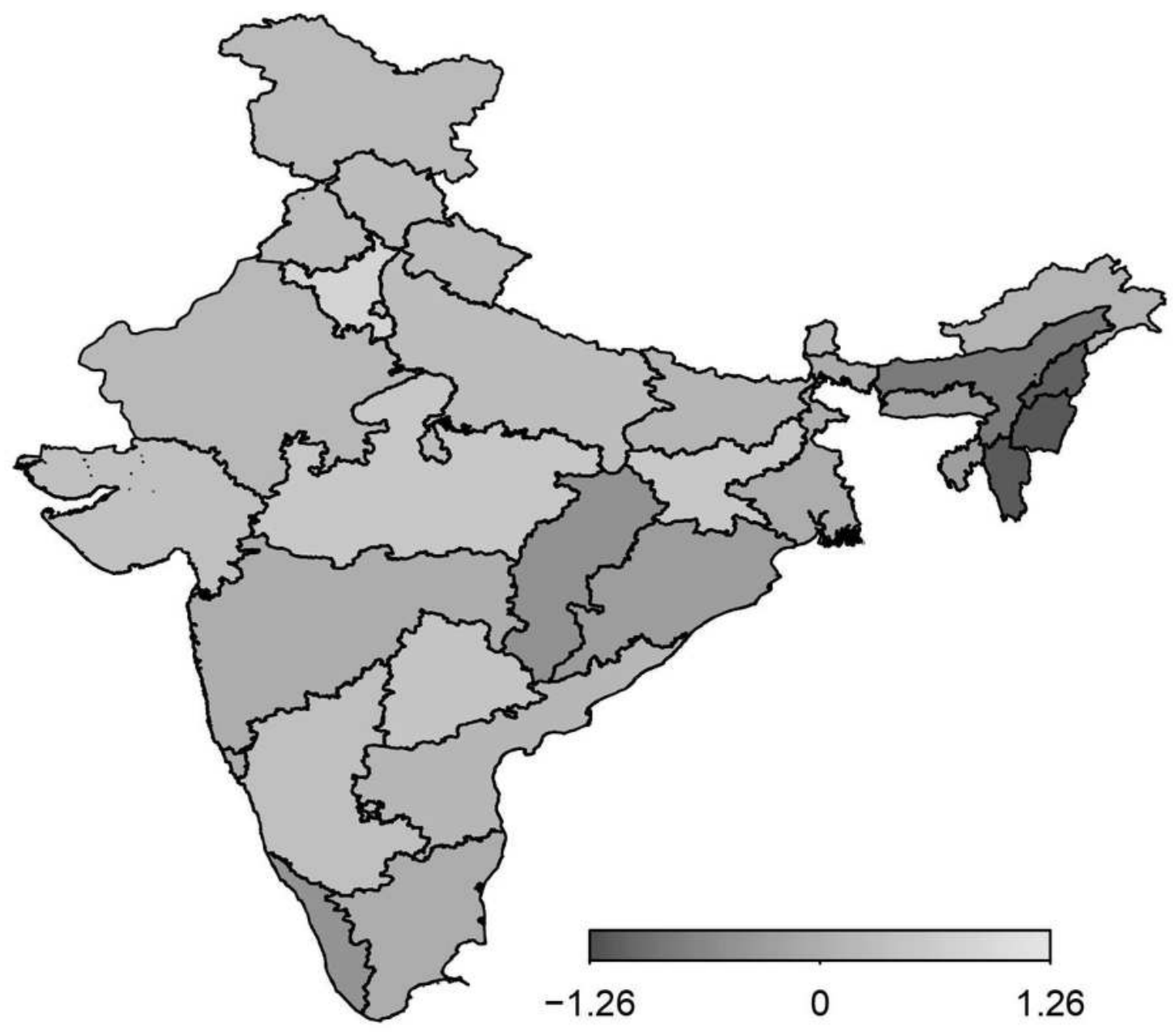

Figure 4

Residual spatial effect to childhood anaemia. Colour ranges from black to white representing low to high risk of childhood anaemia. Note: The designations employed and the presentation of the material on this map do not imply the expression of any opinion whatsoever on the part of Research Square concerning the legal status of any country, territory, city or area o bbnhjr of its authorities, or concerning the delimitation of its frontiers or boundaries. This map has been provided by the authors. 


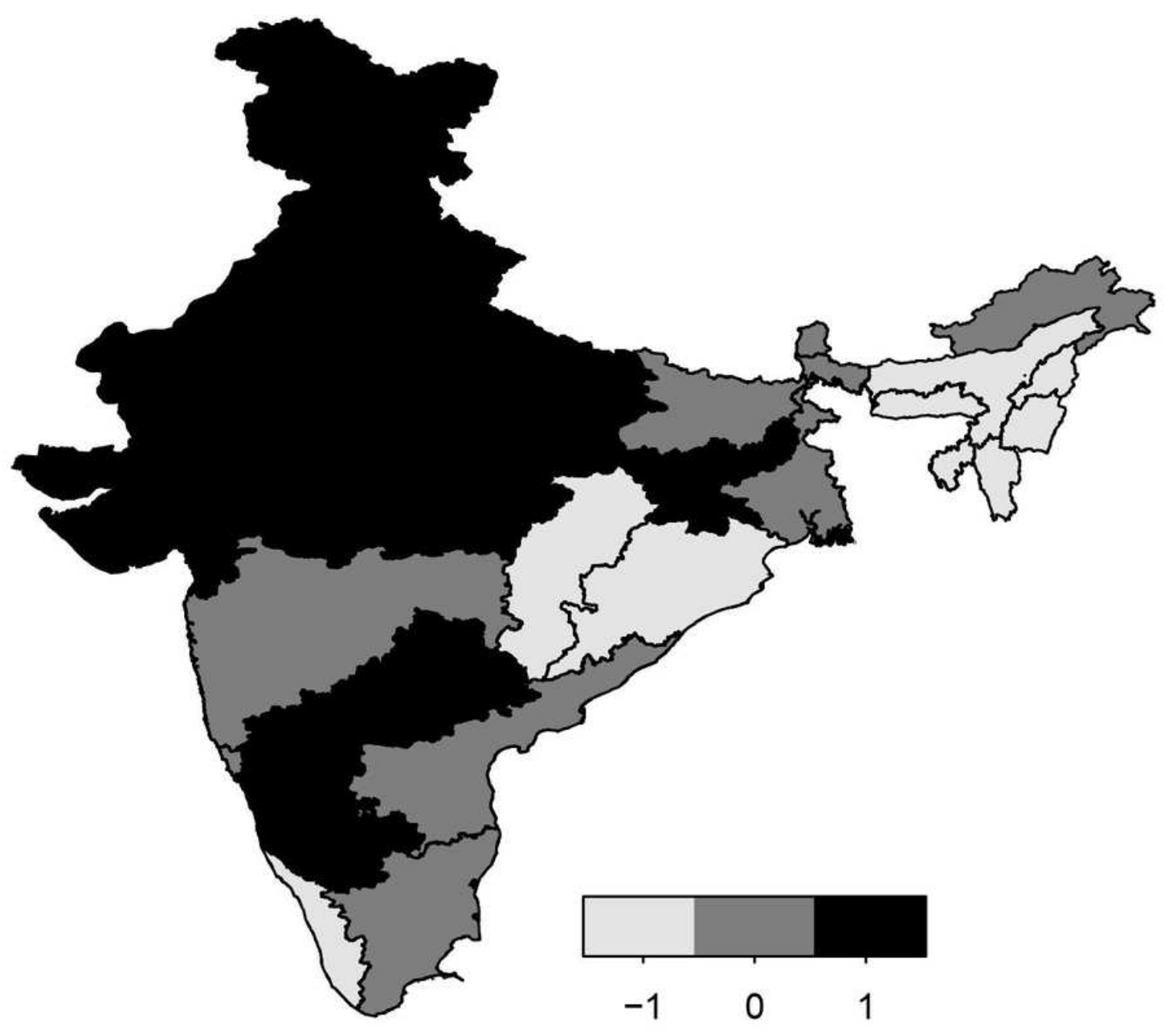

Figure 5

The $95 \%$ credible intervals map for prevalence of anaemia. White: negative effect; light black: insignificant effect; black: positive effect. Note: The designations employed and the presentation of the material on this map do not imply the expression of any opinion whatsoever on the part of Research Square concerning the legal status of any country, territory, city or area o bbnhjr of its authorities, or concerning the delimitation of its frontiers or boundaries. This map has been provided by the authors. 


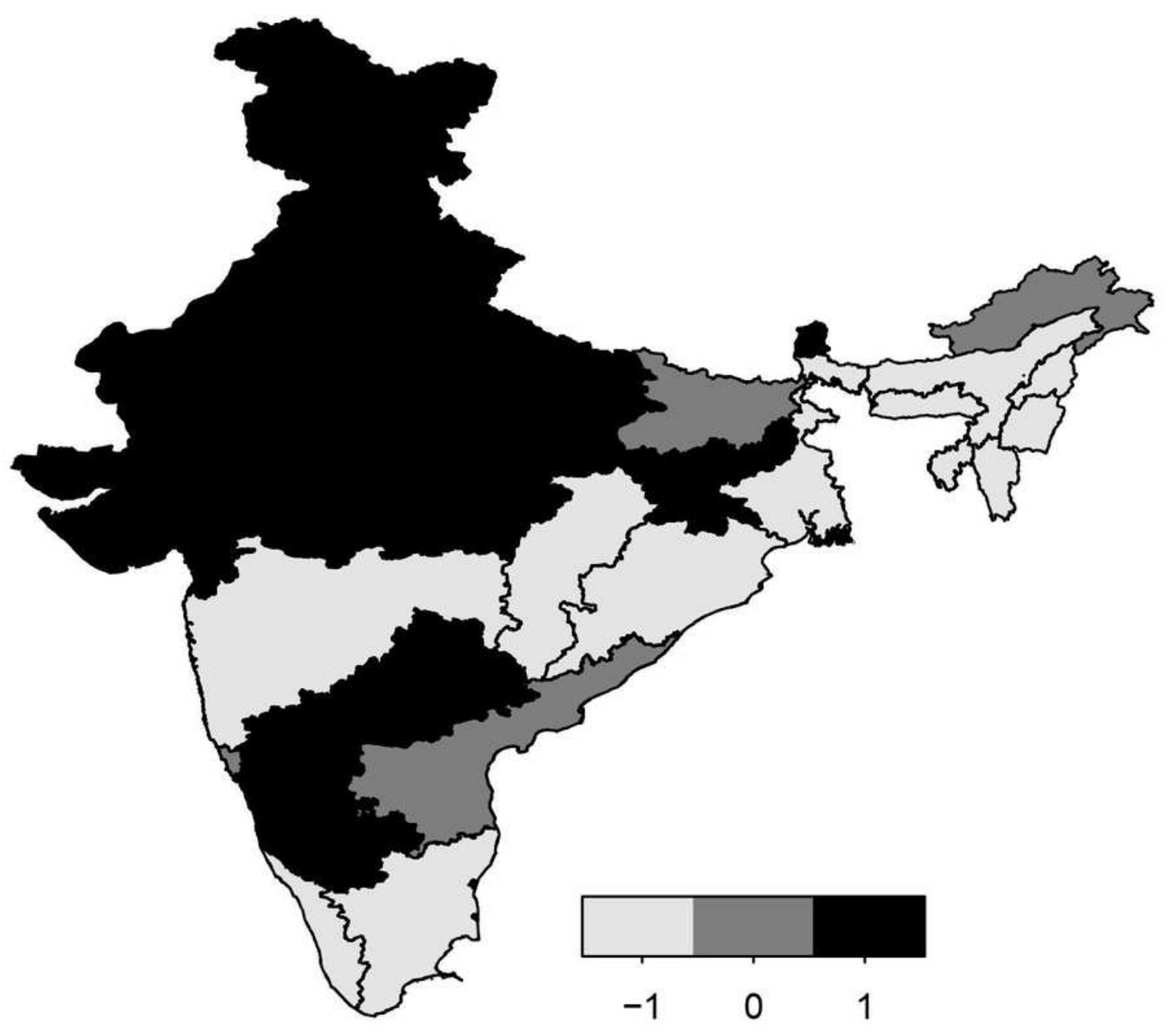

Figure 6

The $80 \%$ credible intervals map for prevalence of anaemia. White: negative effect; light black: insignificant effect; black: positive effect. Note: The designations employed and the presentation of the material on this map do not imply the expression of any opinion whatsoever on the part of Research Square concerning the legal status of any country, territory, city or area o bbnhjr of its authorities, or concerning the delimitation of its frontiers or boundaries. This map has been provided by the authors. 